\title{
Proposed improvements in wave energy converter of oscillating water column (WEC-OWC)
}

\author{
R. Borrás-Formoso ${ }^{1}$, R. Ferreiro-García ${ }^{1}$, A. De Miguel-Catoira ${ }^{2}$ and F. Miguélez-Pose ${ }^{3}$ \\ ${ }^{1}$ Department of Industrial Engineering \\ E.T.S.N.y M., A Coruña University \\ Campus of Riazor, 15011 A Coruña (Spain) \\ Phone/Fax number:+0034 981 167000, e-mail: ramon.borras@udc.es, ferreiro@udc.es \\ ${ }^{2}$ Department of Energy and Propulsion \\ E.T.S.N.y M., A Coruña University \\ Campus of Riazor , 15011 A Coruña (Spain) \\ Phone/Fax number:+0034 981 167000, e-mail: alberto.demiguel@udc.es \\ ${ }^{3}$ Department of Phisics \\ E.T.S.N.y M., A Coruña University \\ Campus of Riazor, 15011 A Coruña (Spain) \\ Phone/Fax number:+0034 981 167000, e-mail: fermigue@udc.es
}

\begin{abstract}
The aim of this paper is to show some design improvements on converters oscillating water column (OWC) versus conventional OWC, focusing on a newly patented design, OWC with Differential Pressure Storage Tanks (DPST). In this research work, a short review of the principles of operation and the results obtained for each one in relation to energy efficiency and regularity of electricity delivered to the grid are described. Apart some known innovations published so far in scientific journals, it will be discussed in more detail a new design (protected by patent) that tries to overcome some major performance problems in both conventional and improved OWC proposed up today such as intermittent flow through the turbine and the bi-directional flow. It is concluded that there are feasible to implement innovations that can lead to improvements with respect to OWC currently in operation.
\end{abstract}

\section{Key words}

Ocean Energy; Wave Energy Converter (WEC); Oscillating Water Column (OWC); OWC-DPST.

\section{Introduction}

The waves are in fact a very concentrated form of solar energy. The heat from the sun warms the earth at different rates causing air to flow from area to area depending on temperature differentials. The winds interact with the uppermost layers of the oceans; as the wind blows tangentially to the ocean surface it causes the particles to rotate in a circular motion. Over a large enough area this rotation penetrates deeper into the surface creating larger waves. The rotating motion of the water particles is stored kinetic energy and the gradual phase shift in time and space over a length perpendicular to the wave front sets up the moving wave pattern, which is essentially progressing waves of potential energy.

The most basic information about a wave is its height (trough to crest). The power in a wave is roughly proportional to the square of the height. The distance between successive crest is the wavelength and the time it takes between the crests is the wave period and is typically 8 seconds in the North Atlantic. [1]

Estimates published in 2011 quantified the annual energy of the wave energy resource in $29500 \mathrm{TW} \cdot \mathrm{h} / \mathrm{yr}$. The energy of the waves for Europe is estimated $1400 \mathrm{GW} \cdot \mathrm{h}$. The practical extractable amount of ocean energy (how much will be utilized) is a question of economy, environmental concerns, alternative options, and the development and demonstration of reliable ocean energy technologies leading to positive environment impact. [2] [3]

It can read in the report: Priority should be given to demonstrate a selection of different operating principles, in order to identify the most efficient and reliable components, power take off systems, mooring systems, electrical interconnections and grid connections. In parallel, priority should be given to integrate the learning from this field test into basic research, focused on new or improved principles, materials, components and systems leading to more economic second and third generation devices.

Share this aim, in this line of new proposals for Wave Energy Converter (WEC), and more specifically in the Oscillating Water Column (OWC), this paper focuses. 


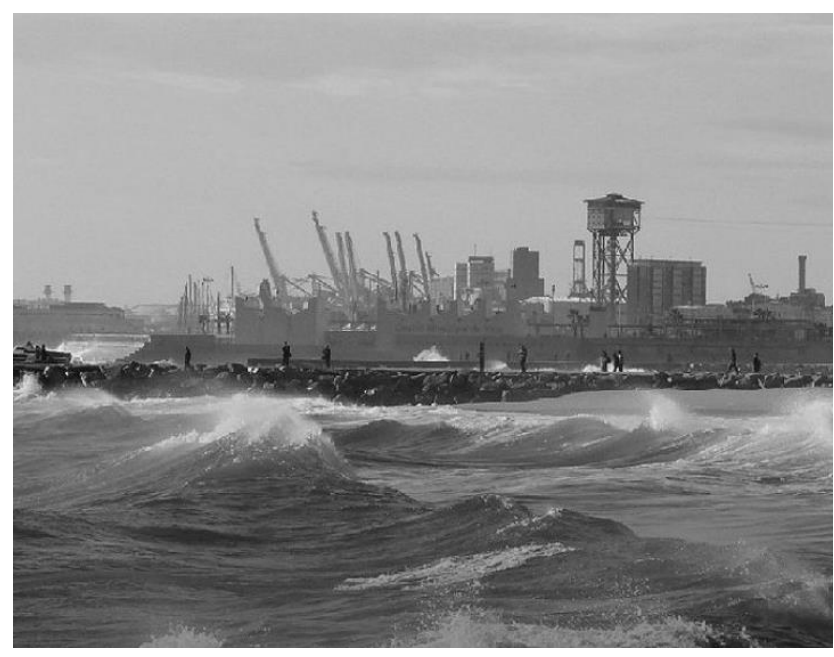

Fig.1. Coastal waves

Besides other aspects the design of devices OWC-WEC study includes several possibilities:

-OWC placement shoreline versus nearshore: OWC devices can be placed on the shoreline where the waves break or near the shore. The near shore devices are fixedly moored to the ocean bottom in the same manner as offshore wind turbines or slack moored so as to respond to changes in mean water level (i.e. tides). In general, the wave energy offshore is greater than that at the shoreline, but the installation and maintenance costs increase. In some areas, wave energy concentration near shore through natural phenomena such as refraction or reflection occurs. Turbine design: For the past twenty years, most OWC research has focused on the Wells Turbine as the solution to bidirectional flow. Even though this turbine is not outdated, the wave energy industry may benefit from exploring new schemes.

-Power electronics: With regards to power electronics , constructing an inverter especially for WEC applications would enhance operation. Since waves are irregular in frequency and size, induced voltages in the generator vary. Hence, the power developed by any of the WECs will be irregular. For this reason, an inverter is needed to smooth the output power. Current research simply states that voltage source inverter control surpasses current source inverter control for better efficiency . In addition to maximizing power output and stabilizing grid connections with the inverter, the WEC might require a bidirectional inverter to provide power back into the machine for electrical damping.[4]

\section{Conventional OWC converter}

The way of working of a conventional converter OWC, explained in a simplified way from Figure 1, is as follows: when the wave reaches the converter, the water level inside the chamber, inside, is lower than that outdoors. It will start to ascend the water level in the chamber, in the inside, by compressing the air during the travel upward in the water column, and this compressed air operated an air turbine that drives an electrical generator. This process will continue until the water column reaches its top level. When the wave, on the outside, withdraws it will begin the downward travel of the water column, the increased volume of air inside the chamber will result in a decrease in pressure, below the atmospheric, and this pressure drop will result in a flow of air, contrary to the previous, driving back to the turbine. It is customary to employ selfrectifying turbines, for example the Wells, Dennis-Auld, McCormick or the reaction-self-rectifying ones that keep the rotation direction regardless of the direction of air flow. The use of self-rectifying turbines, solving a problem in a satisfactory manner, has the advantage of leverage both routes of the column of water for energy conversion. It's already very experienced air turbines and with a mature technology.

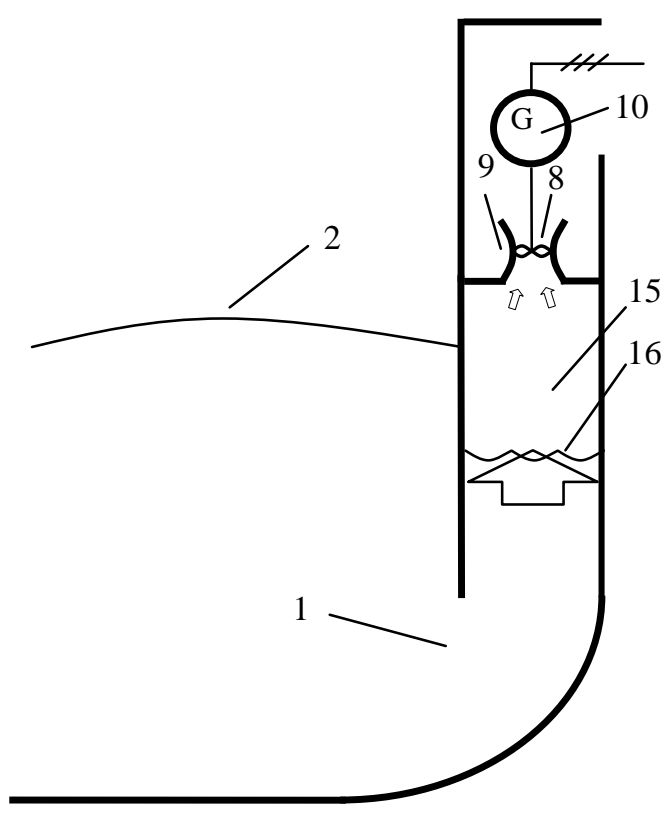

Fig. 2. Conventional OWC Converter

However, by the way these converters work presented several weaknesses arising from the fact that the working, air, fluid flows are [5]:

a) variable in amplitude

b) variable in direction

c) intermittent

d) non-controllable.

Let's look briefly at the implications of each of these features.

a) both the process of compression during the travel upward in the water column, and the suction during the descending route, are not constant pressure. This gives rise to very variable amplitude air flows because the pressure in the chamber is very variable. The effect is that the torque provided by the turbine will also be variable and zero in much of the cycle. Furthermore, in addition to other problems, it will lead to sub-optimal operating conditions (maximum performance condition) and therefore a low performance of the conversion will be obtained. The operating range is very narrow for good performance [6]. The sudden lifting of the pressure in the chamber can cause failure to the blades [7]. The phenomenon of "stalling" makes fall performance from certain flows. [8] 
On the other hand, for the sizing of turbine and electrical generator will have to consider the maximum values of power and torque, well above the average values.

(b) That the air flow is variable in its sense implies that:

1st: or well next is the grinding of the airflow if using a turbine conventional type, i.e. for one direction of flow, and therefore with greater performance, but that requires the use of various valves and elbows in the ducts in the changes of direction with the consequent effect of pressure drops and losses in the conversion.

2nd: or well used an self-rectifying turbine, leading to a significantly lower level of efficiency [9].

(c) That there is a change in the direction of the flow of air in the turbine vent already implies, mathematically, that the flow should undergo zero twice per cycle, i.e., two moments in which no energy being transferred to the turbine. But in addition, when the level of the water column reaches its lower level and from the air in the chamber pressure equal to atmospheric pressure, it will take a while until it begins its upward motion and one while longer until you get to compress the air in the chamber at a pressure sufficient to produce an air flow rate through the turbine to transmit torque. Up to that moment no energy is transferred to the turbine. Something similar happens when the water column is at its top level. By this, it is clear that, during much of the cycle, energy is not being transferred to the turbine. The converted energy is therefore intermittent.

(d) The three above points suggest that air through the turbine flows are highly variable, which means that it is not used as machine driven by the turbine to a three-phase alternator directly connected to the network. A doubly-fed induction generator can be used. Another option is to resort to double conversion rectification-inversion with static elements.

It can be used a turbine controller system acting on a variable blade distributor, to partly mitigate the effects of flows highly variable. In any case, this type of converter control poses major theoretical and practical problems.

It should be added to the above that, inevitably, there will be salt water particles crawls which will impact on the blades of the turbines with the undesirable effects of erosion and fouling. Another problem, from the environmental point of view, is the high noise coming from the turbine air outlet in the peaks of greater speed, which prevents these converters from being located in the vicinity of inhabited areas.

The proposed WEC-OWC, with differential pressure storage tanks (DPST) is designed to avoid many of the disadvantages of conventional OWC converters.

\section{U- OWC converter}

It is a proposal of improvement over conventional OWC built on breakwater. This has an additional vertical duct extending along the whole wave-beaten wall, as shown in
Fig.3. It is hoped that a better performance due two reasons: First, the U-OWC has an eigenperiod greater than the eigenperiod of a conventional OWC. Second, the amplitude of the pressure fluctuations on the opening of a $\mathrm{U}-\mathrm{OWC}$ is greater than the amplitude of the pressure fluctuations on the opening of a conventional OWC . For the first reason, a U-OWC can give performances better than those of a conventional OWC both with swells and large wind waves. For the second reason, can give performances better than those of a conventional OWC also with small wind waves. The performances have estimated assuming that the plant generates a progressive wave which is superimposed on the standing wave due to the reflection of the incident wave. Moreover, under the same weight, a breakwater embodying the U-OWC has a safety factor slightly greater than the safety factor of a breakwater embodying the conventional OWC. [10]

The efficiency of an OWC based plant is given by $\eta=n_{\text {owc }} \bullet \eta_{t} \bullet \eta_{e}$ where $\eta_{\text {owc }}$ is the efficiency of the OWC (usually referred to as the energy extracting device), $\eta_{t}$ is the turbine efficiency (usually referred to as the energy converting device) and $\eta_{e}$ is the electrical generator efficiency (or generator and electronic converter, if any).

The objective is to arrive at a configuration that can provide a high overall efficiency spanning the range of input conditions. A high efficiency of one component in the chain at one operating condition is likely to be misleading and insufficient to characterize performance. The turbine efficiency is a nonlinear function of the flow coefficient. [11][12]

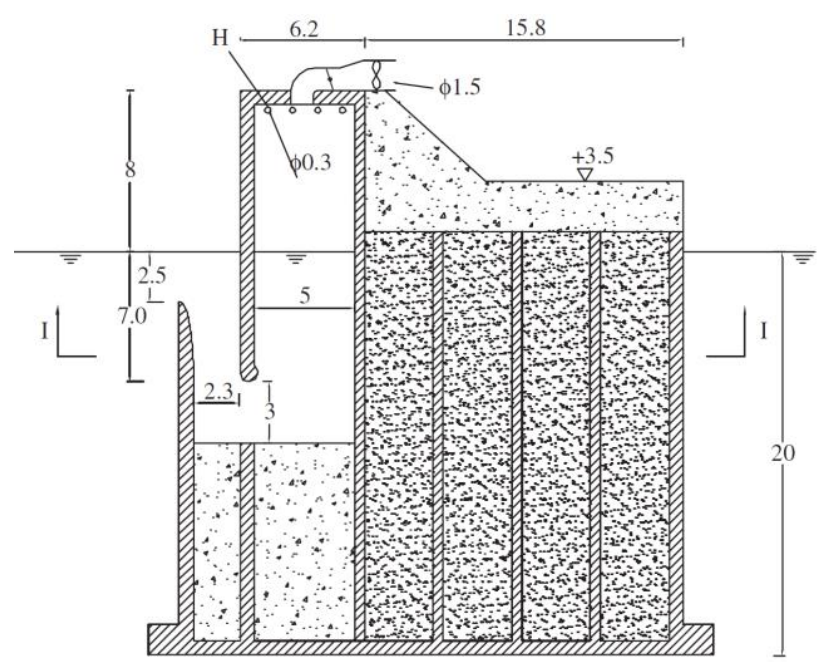

Fig.3. U-OWC Converter

The air turbine of an OWC is subject to much more demanding conditions than the turbines in any other application, including wind turbines. Indeed the flow through the turbine is reciprocating (except if a rectifying system is provided, which so far has been found unpractical), and is random and highly variable over several time scales, ranging from a few seconds to seasonal variations. It is not surprising that the timeaveraged efficiency of an air turbine in an OWC is substantially lower than that of a (water, steam, gas, wind) turbine working in nearly steady conditions. [13] 
The Wells turbine has inherent disadvantages: lower efficiency and poorer starting characteristics in comparison with a conventional unidirectional turbine.

In this WEC, the only difference with the conventional OWC is that the U-OWC has an additional vertical duct extending along the whole wave-beaten wall. The big difference between the performances is apparent even if we have neglected the head losses of the water flow in the conventional OWC. However, the production of electric power of the U-OWC should remain well greater than the production of electric power of the conventional OWC.

The U-OWC does not suck air through the opening in the wave-beaten wall. In principle this is a good thing, in that it is difficult to foresse what may happen if the plant sucks air though the opening in the wave-beaten wall.

The U-OWC has an eigenperiod greater than the eigenperiod of the conventional OWC, which leads the UOWC to give some much better performances with swells and large wind waves. The opening of the U-OWC is higher than the opening of the conventional OWC, which leads the U-OWC to give some better performance also with small wind waves. In heavy sea states, the conventional OWC is expected to suck air through the opening in the wave-beaten wall, for some short span of time; not so the U-OWC. Under the same weight, a breakwater embodying the U-OWC has a safety factor slightly greater than the safety factor of a breakwater embodying the conventional OWC. [10]

\section{Two Chambers OWC converter}

This OWC - wall mounted with passing waves rather than shore-mounted with full-frontal incident waves- consists of two chambers (denoted Chamber $1 / 2$ and Chamber $2 / 2$ in Fig. 4).

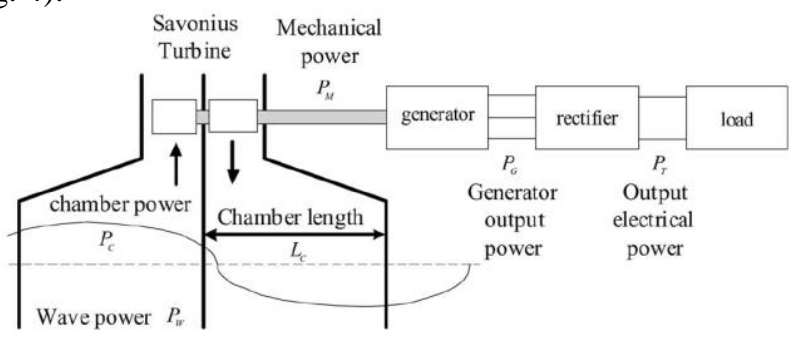

(a)

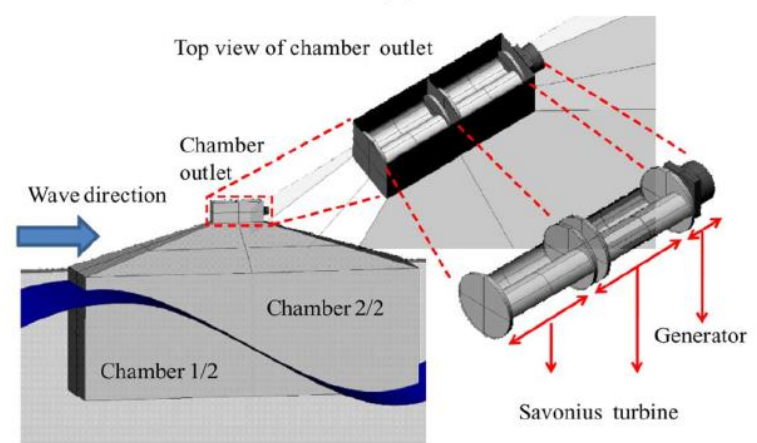

(b)

Fig.4. Two Chambers OWC Converter. a) Schematic of twosegmented OWC, turbine an direction incoming wave.

b) Construction of the developed OWC
On the top of each column is a turbine which converts the airflow power into rotary mechanical power. The two turbines are connected in line with a three-phase generator. This means that individual chambers will separately deliver power to the corresponding turbine with a phase difference. The torque acting on the turbines will then be converted into electric power via the generator; the power conversion pulsates with the alternating airflow but it is smoothed by the fact that the two columns work out of phase. To connect the generator output to the grid, a power electronic inverter is needed on the output of the dc link. The use of multiple chambers and mechanical coupling of the chamber turbines will reduce the power pulsation and hence the $\mathrm{dc}$ link energy storage requirement, if power pulsation onto the grid is required to be limited. From the electric machine design process, the generator can be designed from the specification determined from the turbine output characteristics. [14]

\section{OWC-DPST converter}

Figure 2 shows a simplified diagram of a conventional OWC converter. The extraordinary simplicity of its principle of operation can be seen. The level of water inside the chamber tries to follow, with a certain delay, the level of the water from the outside.

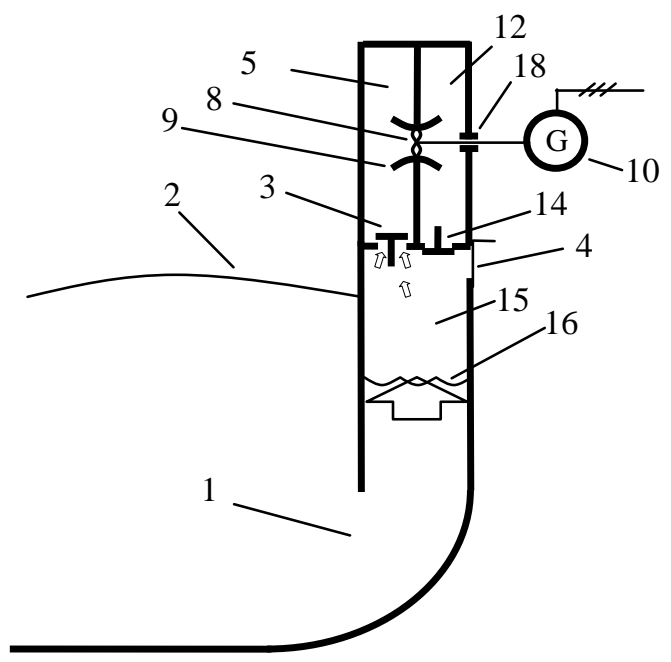

Fig.5. OWC-DPST Converter

Figure 5 shows, also in a simplified manner, the OWCDPST converter (Differential Pressure Storage Tanks)[15]. The number 5 represents the storage tank of high pressure, HPT, which introduces, through the remote operated valve $3, \mathrm{HPV}$, the compressed air from the chamber during the upward travel of the oscillating water column. Tank 5 pressure is a pressure gauge, relative, positive pressure. The low pressure storage tank, LPT, is represented with the number 12 . From this tank air is extracted by suction, through a remote operated valve 14 (LPV) during the downstroke of the water column. In this tank the gauge, relative pressure is negative.

The vent valve (VV) marked with the number 4, allows more efficiently the process of filling and emptying of storage tanks. It is a remote operated valve which opens before the water column reaches its upper level, once the 
charging period is completed, allowing the pressurized air which is still in the chamber to be evacuated into the atmosphere, thus permitting the water levels to continue to rise. This valve should open at the end the period of air suction from the LPT tank, allowing air to enter the chamber until the pressure is equal to the outside atmospheric pressure.

Between one storage tank and the other there will be a leap in pressure, differential pressure, which, if they have sufficient volume, allows a nearly continuous and constant air flow over the conventional high performance turbine, which will drag the electric generator, for example a three-phase alternator, which can be attached directly to the mains. Another possibility is to use as a generator the doubly-fed induction generator (DFIG) as it can work as a synchronous machine, rotating at a more suitable speed, such as it is done with the wind turbines. The volumes of storage tanks have to be much greater than the volume of the chamber.

\section{OWC-DPST. Detailed operating description}

Last paragraph gave one sufficient explanation to understand the operation. A full description of the way of operation will be posted in this section.

This converter is controlled by a processor which receives the signal from the pressure transducers of the high pressure storage tank, the low pressure accumulator tank and the pressure from the chamber as well as water level sensors of the inside and the outside of the chamber. From the processor the command order is given to HPV, LPV and VV valves and turbine power is controlled by adjusting the flow rate, for example by opening or closing the passage of air to a greater or lesser number of pallets, as it is done in the steam turbines.

Following in Figure 2, when the water level in the oscillating column chamber is at its lowest, the air pressure in the chamber (15) is equal to atmospheric pressure (relative pressure gauge, zero) to open the venting valve. HPV valve that connects the oscillating water column chamber with HPT high-pressure accumulator air tank, as well as the valve LPV (14) that communicates the camera from the oscillating water column with LPT low-pressure accumulator tank (12), are closed. Then, the venting valve is closed. When the upward movement of the water column starts, the air in the chamber pressure increases slightly, but all air remains confined within the camera. The water level will keep rising and the air pressure will continue to increase until the moment in which the air in the chamber pressure exceeds pressure inside the high-pressure accumulator tank, HPT. From that moment it will be given the order of opening valve HPV and air will flow naturally through the valve HPV open, slightly rising pressure in the highpressure accumulator tank.

When completed the introduction of air into the high pressure accumulator tank, the HPV closes and opens the venting valve $\mathrm{VV}$ to release air in order to reach the atmospheric pressure in the chamber. The water level in the chamber will match the level of water in the outside. Once the water in the chamber reaches its highest level, the venting valve $\mathrm{VV}$ is closed and as the water level lowers, the pressure in the chamber will lower as well. As soon as the pressure in the oscillating water column chamber drops below the existing in the low pressure accumulator tank LPT, the valve LPV will opened and air will flow naturally from the inside of the low pressure accumulator tank LPT to the chamber. When the passage of air from the LPT towards the chamber stops, it will close the LPV valve, and then it will open the venting valve $\mathrm{VV}$, giving air to reach the atmospheric pressure in the chamber. The water level of the oscillating column will drop until reaching the lower level. From here the cycle is repeated.

When the HPT and LPT accumulator tanks reach the desired pressures, the turbine can be fed by air flowing from the HPT to LPT, remaining pressures from both accumulator tanks significantly constant, if they have a high enough volume. In order it can work in a stable, continuous way, the air consumption of the turbine (mass flow) in a cycle will have to be equal to the amount of air that enters a cycle in the HPT and also to the amount of air extracted from the LPT throughout a cycle.

If you want the turbine to power an electric generator (three-phase alternator) which will be attached to the network, it is imposed that the rotational speed is fixed. To provide a certain power, the volumetric flow rate shall be function of the pressure in the tanks. If the maximum usage should be required, then, it must be ensured that the turbine works in the condition of maximum performance or at least in the environment of that maximum and that implies that the pressure in the tanks have to remain substantially constant and this means that the higher the volume of accumulator tanks is, the lower the pressure fluctuation will be. So the convenience of operation of the turbine between air defined pressure tanks is justified.
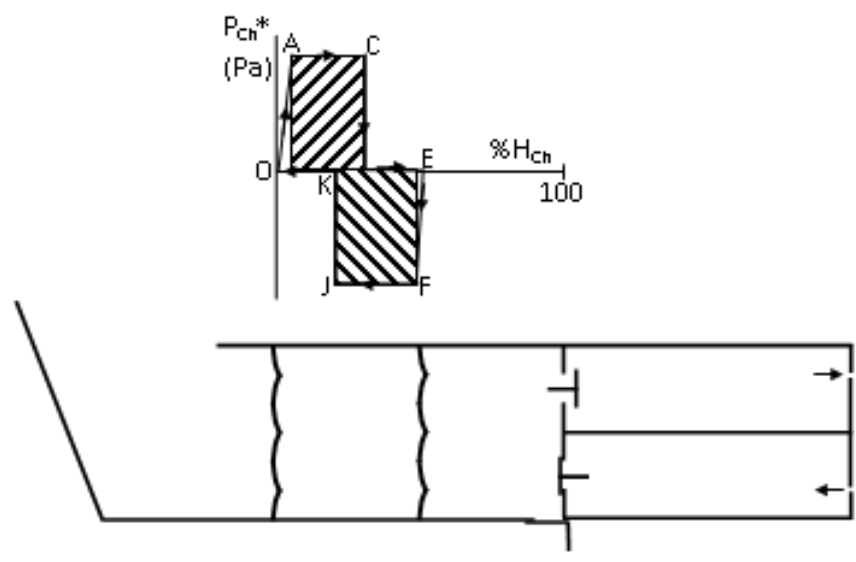

Fig. 6 P-V cycle for the OWC_DPST converter

It is important to note that while some air flows are produced from the camera to the outside, and conversely, when $\mathrm{VV}$ valve is open, the average value of the mass flow over the cycle $(\mathrm{kg} / \mathrm{s})$ is constant inside the converter.[15] 
Converter work can be explained through the theoretical P-V cycle, as shown in Figure 6. [16]

\section{Conclusion}

In view of the above in the preceding paragraphs, with the proposed wave converter design improvements could be obtained over conventional designs, which can be highlighted in the following points:

Energetic transformation performance comes from the accumulation pressure. The accumulator tank pressures that maximize the performance of the converter can be adjusted.

- Francis unidirectional flow turbines, with greater efficiency, can be used instead of the Wells of bidirectional flow.

As the converter works at a steady, stable, smooth speed, dimensioned machines are not needed to work in power and torque peaks. Therefore, for a given power production, much smaller and cheaper and less powerful machines can be used.

- To adjust the operation mode to the different wave conditions, the most suitable generator can be the DFIG

- A small wave height, not enough to be useful for a conventional OWC, could be capable of generating electricity in an OWC-DPST

- $\quad$ It could prevent erosion and deposits on blades of the turbine by impact of dragged salt water particles, requiring less maintenance cost.

- High noises coming from the output of the turbine, be avoided, which means less environmental impact

- $\quad$ Studying the converter performance using the cycle diagram on the $\mathrm{P}-\mathrm{V}$ plane allows to understand more easily how to work.

\section{References}

[1] Dorrell, D. et al. "Review of wave energy resource and oscillating water column modelling". 39th International Universities Power Engineering Conference. Vol.1 . 2004
[2] Nielsen K. 2012. "Ocean Energy Technology Study". DanWEC. Technical Report No.1 for The Alliance for Offshore Renewables.

[3]Huertas, C. et al. First output of the Sowfia Project: Streamlining of Ocean Wave Farms Impact Assessment. IEEE 2011

[4]Muetze, A.Vining, J. "Ocean Wave Energy Conversion- A Survey" (pp1410-1417). University of Wisconsin. IEEE 2006.

[5] Borrás-Formoso, R. et al. "Making use of coastal wave energy: a proposal to improve oscillating water column converters". Dyna-Colombia 81(185), pp 211-218, 2014

[6] Setoguchi, T. et al. "A review of impulse turbines for wave energy conversion", Renewable Energy.2001. 23, 261-292.

[7] Brito-Melo, A. et al. "Analysis of Wells turbine design parameters by numerical simulation of the OWC performance", Ocean Engineering. 2002. 29, 1463-1477 .

[8] Alberdi, M. et al."Complementary control of oscillating water column-based wave energy conversion plants to improve the instantaneous power output",2011. IEEE Transactions on Energy Conversion.26-4 1021-1032

[9]Maeda, H et al. "Performance of an impulse turbine with fixed guide vanes for wave power conversion". Renewable Energy. 17 pp.533-547. 1999

[10]Boccotti, P. "Comparison between a U-OWC and a conventional OWC". Ocean Engineering. 34, pp 799-805. 2007

[11] Jayashankar, V. et al. "A twin unidirectional impulse turbine topology for OWC based wave energy plants". Renewable Energy 34 pp. 692-698. 2009

[12]Thakker, A. et al. "Effects of turbine damping on performance of an impulse turbine for wave energy conversion under different sea conditions using numerical simulation techniques". Renewable energies. 29 pp.2133-2151. 2004

[13] Falcao, A. "Wave energy utilization: A review of the technologies". Renewable and Sustainable Energy Reviews. 14 pp.899-918. 2010

[14] Min-Fu, H. et al. "Development of a Wave Energy Converter Using a Two Chamber Oscillating Water Colum". IEEE Transsactions on Sustainable Energy. Vol 3, No.3. 2012

[15] Borrás-Formoso, R. et al. "Convertidor undimotriz de columna de agua oscilante, OWC-DPST" ES201230530. OEPM.

[16] Borrás-Formoso, R. et al. "Performance and Theoretical cycle of a wave oscillating water column converter with Differential Pressure Storage Tanks". Journal of Maritime Research. Accepted 2014. 